\title{
Opportunistic Infection in Hospitalised Patients with Inflammatory Bowel Disease
}

\author{
Jin-Qiu Zhou ${ }^{1}$, Zhang-Min Meng ${ }^{1}$, Tao Zhang ${ }^{2}$, Xing-Tao Jing ${ }^{3}$ and Hua-Tian Gan ${ }^{1}$ \\ ${ }^{1}$ Department of Geriatrics Medicine and the Center of Gerontology and Geriatrics, West China Hospital, Sichuan University, Chengdu, \\ Sichuan, China \\ ${ }^{2}$ Department of Gastroenterology, Nanchong Central Hospital, Nachong, Sichuan, China \\ ${ }^{3}$ Department of Otolaryngology, West China Hospital, Sichuan University, Chengdu, Sichuan, China
}

\begin{abstract}
Objective: To investigate the incidence, clinical features, and risk factors of opportunistic infections in elderly patients with inflammatory bowel disease (IBD).

Study Design: Observational study.

Place and Duration of Study: Department of Digestive and Geriatrics Center, Sichuan University West China Hospital, China between January 2012 and January 2019.

Methodology: Patients ( $\geq 18$ years) with IBD were enrolled in this study. Clinical data from the infected elderly group (age $\geq 60$ years), non-infected elderly group (age $\geq 60$ years) and infected adult group (age: 18-59 years) were compared. Logistic regression analysis was used for risk factors associated with opportunistic infection.

Results: A total of $8.9 \%(307 / 3,456)$ of patients with IBD had opportunistic infection. The opportunistic infection rate of elderly group was $16.5 \%$ (80/485), which was significantly higher than that of adult group $(7.6 \%, 227 / 2,971, p<0.05)$. Compared with infected adult group or non-infected elderly group, infected elderly group had less fever and leukocytosis, but more hypoproteinemia and several activities $(p<0.05)$. Cytomegalovirus and Epstein-Barr virus were the most common agents in elderly group and adult group, respectively. Multiple episodes (three or more) were more common in infected elderly group; the time of opportunistic infections was associated with systemic inflammatory reaction syndrome (SIRS, $p<0.05$ ). Logistic regression analysis showed that age $\geq 60$ years, corticosteroids, immunosuppressive and biological agents were risk factors for opportunistic infections in patients with IBD.

Conclusion: Hospitalised elderly IBD patients, receiving corticosteroids, immunosuppressive, and biological agents, are at higher risk for infection. The symptoms of opportunistic infections in elderly patients are atypical, but they are prone to multiple infections with poor prognosis.
\end{abstract}

Key Words: Elderly patients, Inflammatory bowel disease, Opportunistic infection, Systemic inflammation reaction syndrome.

How to cite this article: Zhou JQ, Meng ZM, Zhang T, Jing XT, Gan HT. Opportunistic Infection in Hospitalised Patients with Inflammatory Bowel Disease. J Coll Physicians Surg Pak 2020; 30(10):1015-1020 .

\section{INTRODUCTION}

Inflammatory bowel disease (IBD) is a chronic relapsing and remitting disease, mainly including Crohn's disease (CD) and ulcerative colitis (UC), and the incidence rate is increasing throughout Asia. ${ }^{1,2}$

Correspondence to: Hua-Tian Gan, Department of Geriatrics Medicine and the Center of Gerontology and Geriatrics, West China Hospital, Sichuan University, Chengdu 61004, China

E-mail: zhoujinqiu13@163.com

Received: July 25, 2020; Revised: October 06, 2020;

Accepted: October 19, 2020

DOI: https://doi.org/10.29271/jcpsp.2020.10.1015
A bimodal age curve for IBD incidence has been suggested in epidemiological studies, with the first peak occurring at 20-30 years and a second small peak occurring at 60-70 years, correlating with the approximately $10-15 \%$ of cases that manifest after the age of 60 years. ${ }^{3}$ Along with the worsening increase in population aging, IBD will become an increasingly serious problem among elderly patients, by affecting their quality of life and even life expectancy. Corticosteroids, immunosuppressants, and biologic medications can be used alone or in combination to treat patients with moderate to severe IBD. Each treatment strategy can effectively combat the disease, but increase the risk of opportunistic infection. ${ }^{4}$ Elderly patients are at higher risk of opportunistic infection due to a low level of immunity, impaired intestinal mucosal barrier function, malnutrition, and intestinal flora imbalances. ${ }^{4-8}$ Previous study indicated that IBD patients (65 years or older) had 2-to-3 fold increased infection risks compared with younger patients with IBD. ${ }^{9}$ 
Table I: Comparetion of clinical characteristics between infected elderly group and infected adult group/non-infected elderly group.

\begin{tabular}{|c|c|c|c|c|c|}
\hline & $\begin{array}{l}\text { Infected elderly group } \\
\qquad(\mathrm{n}=80)\end{array}$ & $\begin{array}{l}\text { Infected adult group } \\
\qquad(\mathrm{n}=227)\end{array}$ & $\begin{array}{l}\text { Non-infected elderly group } \\
(n=405)\end{array}$ & P1* & P2* \\
\hline Sex, male/female, $\mathrm{N}$ & $50(62.5 \%) / 30(37.5 \%)$ & $132(58.1 \%) / 95(41.9 \%)$ & $235(58.0 \%) / 170(42.0 \%)$ & 0.496 & 0.457 \\
\hline Age, (mean \pm SD) (years) & $68.59 \pm 6.63$ & $36.09 \pm 12.20$ & $66.72 \pm 8.26$ & $<0.001$ & 0.050 \\
\hline $\mathrm{UC} / \mathrm{CD}, \mathrm{N}$ & $68(85.0 \%) / 12(15.0 \%)$ & $130(57.3 \%) / 97(42.7 \%)$ & $350(86.4 \%) / 55(13.6 \%)$ & $<0.001$ & 0.737 \\
\hline Hospitalization days $\{$ median (IQR)\} (days) & 19(17-23) & $17(15-20)$ & 16(12-19) & $<0.001$ & $<0.001$ \\
\hline Expense $\{$ median (IQR)\} (Yuan,RMB) & $12301.21(8033.73-25591.79)$ & $11340.12(5776.94-18621.70)$ & 10653.92(7497.06-16720.47) & 0.041 & 0.047 \\
\hline Fever, N(\%) & $24(30.0 \%)$ & $98(43.2 \%)$ & $72(17.8 \%)$ & 0.038 & 0.012 \\
\hline Diarrhoea, N(\%) & $67(83.8 \%)$ & $192(84.6 \%)$ & $296(73.1 \%)$ & 0.860 & 0.045 \\
\hline Abdominal pain, $\mathrm{N}(\%)$ & $58(72.5 \%)$ & $190(83.7 \%)$ & $258(63.7 \%)$ & 0.029 & 0.131 \\
\hline Abdominal distension, $\mathrm{N}(\%)$ & $64(80.0 \%)$ & $160(70.5 \%)$ & $275(67.9 \%)$ & 0.099 & 0.031 \\
\hline Abdominal mass, $\mathrm{N}(\%)$ & $4(5.0 \%)$ & $26(11.5 \%)$ & $20(4.9 \%)$ & 0.095 & $>0.999$ \\
\hline Anemia (<120g/l), N(\%) & $51(63.8 \%)$ & $173(76.2 \%)$ & $230(56.8 \%)$ & 0.031 & 0.249 \\
\hline Hypoproteinemia $(<35.0 \mathrm{~g} / \mathrm{L}), \mathrm{N}(\%)$ & $53(66.3 \%)$ & $119(52.4 \%)$ & $190(46.9 \%)$ & 0.032 & 0.002 \\
\hline Platelet increase (>300 10A9/L), N(\%) & $19(23.8 \%)$ & $91(40.1 \%)$ & $60(14.8 \%)$ & 0.009 & 0.048 \\
\hline Leukocyte increase(>9.5 10A9/L), N(\%) & $22(27.5 \%)$ & $92(40.5 \%)$ & $99(24.4 \%)$ & 0.038 & 0.564 \\
\hline ESRa increase (>15 mm/L), N(\%) & $55 / 66(83.3 \%)$ & $151 / 172(87.8 \%)$ & $195 / 320(60.9 \%)$ & 0.367 & 0.001 \\
\hline CRPb increasen (>5 mg/L), $\mathrm{N}(\%)$ & $46 / 66(69.7 \%)$ & $128 / 172(74.4 \%)$ & $162 / 320(50.6 \%)$ & 0.462 & 0.005 \\
\hline PCTc increasen (>5 mm/L),N(\%) & $23 / 32 b(71.9 \%)$ & $72 / 90 \mathrm{~b}(80.0 \%)$ & $50 / 120 \mathrm{~b}(41.7 \%)$ & 0.342 & 0.002 \\
\hline \multicolumn{6}{|l|}{ Clinical disease activities } \\
\hline Mild, N(\%) & $0(0.0 \%)$ & $2(0.88 \%)$ & $15(3.7 \%)$ & $>0.999$ & 0.147 \\
\hline Moderate, $\mathrm{N}(\%)$ & $18(22.5 \%)$ & $77(33.9 \%)$ & $151(37.3 \%)$ & 0.057 & 0.011 \\
\hline Severe, N(\%) & $62(77.5 \%)$ & $148(65.2 \%)$ & $239(59.0 \%)$ & 0.042 & 0.002 \\
\hline
\end{tabular}

Table II: Comparetion of pathogens between infected elderly group and infected adult group.

\begin{tabular}{|c|c|c|c|}
\hline N (\%) & $\begin{array}{l}\text { Infected elderly group } \\
\qquad(\mathrm{n}=\mathbf{8 0 )}\end{array}$ & $\begin{array}{l}\text { Infected adult group } \\
\qquad(n=227)\end{array}$ & $\mathbf{p}$ \\
\hline Virus & $53(66.3 \%) *$ & $160(70.5 \%)^{\#}$ & 0.480 \\
\hline Cytomegalovirus (CMV) & $30(37.5 \%)$ & $75(33.0 \%)$ & \\
\hline Epstein-Barr virus (EBV) & $30(37.5 \%)$ & $82(36.1 \%)$ & \\
\hline Other virusesa $^{a}$ & $10(12.5 \%)$ & $23(10.1 \%)$ & \\
\hline Hepatitis virus & $3(3.75 \%)$ & $8(3.5 \%)$ & \\
\hline Bacterial & $36(45.0 \%)$ & $74(32.6 \%)$ & 0.047 \\
\hline Other Bacteriac ${ }^{b}$ & $26(32.5 \%)$ & $34(15.0 \%)$ & \\
\hline Clostridium difficil(CDI) & $9(11.3 \%)$ & $30(13.2 \%)$ & \\
\hline Tuberculosis & $2(2.5 \%)$ & $10(4.4 \%)$ & \\
\hline Fungal and Parasite & $10(12.5 \%)$ & $20(8.8 \%)$ & 0.339 \\
\hline Coinfection with different pathogens ( $\geq 2$ species) & $19(23.8 \%)$ & $31(13.7 \%)$ & 0.036 \\
\hline
\end{tabular}

Table III: Univariate analysis and multivariate analysis of risk factors for opportunistic infection in IBD patients.

\begin{tabular}{|c|c|c|c|c|c|c|}
\hline & p-value & Odds ratio & $95 \% \mathrm{Cl}$ & p-value & Odds ratio & $95 \% \mathrm{Cl}$ \\
\hline Gender: Man & 0.144 & 0.625 & $0.333-1.174$ & - & - & - \\
\hline Age $>60$ years & 0.043 & 2.086 & $1.023-4.253$ & 0.029 & 2.542 & $1.100-5.875$ \\
\hline Smoking & 0.423 & 1.216 & $0.754-1.962$ & - & - & - \\
\hline Aminosalicylic acid & 0.073 & 2.017 & $0.937-4.339$ & - & - & - \\
\hline Corticosteroids & 0.004 & 2.513 & $1.344-4.699$ & 0.028 & 2.133 & $1.086-4.191$ \\
\hline Immunosuppressants & $<0.001$ & 3.335 & $1.763-6.311$ & $<0.001$ & 3.612 & $1.804-7.234$ \\
\hline Biological agents & $<0.001$ & 4.353 & $1.926-9.838$ & 0.003 & 3.772 & $1.565-9.093$ \\
\hline Hypertension & 0.469 & 1.619 & $0.439-5.968$ & - & - & - \\
\hline Diabetes & 0.021 & 3.810 & $1.218-11.913$ & 0.076 & 3.319 & $0.885-11.127$ \\
\hline COPD & 0.356 & 2.156 & $0.422-11.011$ & - & - & - \\
\hline
\end{tabular}

This is an important issue, as there is an increased difficulty in the diagnosis and management of elderly IBD with oppor- 
tunistic infection. Unfortunately, research regarding elderly IBD patients with opportunistic infection in China has been deficient. In this study, the aim was to investigate clinical features, the frequency of and risk factors of opportunistic infections in elderly patients with IBD.

\section{METHODOLOGY}

Patients of 18 years or older identified with IBD at Sichuan University, West China Hospital from January 2012 to January 2019, were included in this observational cohort study. The information of cases was obtained from the inpatient information database and the electronic management inquiry system of three institutions. This study has passed the biomedical ethics review of West China Hospital of Sichuan University (approval number: 2018242). This is an observational study, and informed consent has been exempted by using the medical records obtained from previous clinical diagnosis and treatment. Patients were diagnosed with IBD according to established clinical, endoscopic, and histological criteria. According to the ICD-10 codes of CD or UC of inpatient, the identification of patients has been confirmed.

Patients with IBD, also suffering from acquired immune deficiency syndrome (AIDS), congenital immunodeficiency, or organ transplantation were excluded. Opportunistic infections were classified based on pathogens, including viral [e.g., cytomegalovirus (CMV), herpes simplex virus (HSV), Epstein-Barr virus (EBV)], Escherichia coli, Streptococcus pneumoniae, Clostridium difficile (CDI), Mycobacterium tuberculosis, fungal (e.g., Candida, Histoplasma), and parasitic infections. Supplementary file provided the diagnoses of opportunity infection according to the infection sites and pathogens, and the ICD-10 of pathogens.

According to age and opportunity infection, patients were divided into an infected elderly group and a non-infected elderly group (age $\geq 60$ years), and an infected adult group and a non-infected adult group (age 18-59 years). The infected elderly group was finally divided into a parenteral infection group and an intestinal infection group.

Clinical and analytical data, obtained from the patients, included their gender, current age, the type of IBD (UC or $C D)$, length of hospital stay, treatment expense, clinical feature, laboratory examination, infection pathogens (for infection patients), medical treatments and the prognosis. This data were compared between infected elderly group and non-infected elderly group; infected elderly group and infected adult group.

The disease activity was evaluated by the Mayo score for $U^{10}$ and Crohn's disease activity index (CDAI, for CD). ${ }^{11}$ It was divided into clinical remission (Mayo <3, CDAI <150), mild activity (Mayo 3-5, CDAl 150-220), moderate activity (Mayo 6-10, CDAl 221-450), and severe activity (Mayo 11-12,
CDAI >450).

Systemic inflammatory reaction syndrome (SIRS) criteria are defined as a heart rate $>90$ beats per minute, a respiratory rate $>20$ breaths per minute, a temperature $<36^{\circ} \mathrm{C}$ or $>38^{\circ} \mathrm{C}$ and a white blood cell count $<4000 / \mathrm{mm}^{3}$ or $>12000 / \mathrm{mm}^{3}$. A positive score was defined as $\geq 2$ out of $4 .{ }^{12}$

The quantitative variables with normal distribution are presented as the mean \pm standard deviation (SD), those with skewed distribution as median (IQR), and categorical variables as number (percentage). For between-group comparisons, the Chi-square/Fisher's exact test was used for discrete variables, and independent sample t-test or MannWhitney U-test for continuous variables. Univariate regression and multivariate logistic regression analyses were performed to evaluate the risk factors for opportunistic infection. Correlations between ordered categorical variables were measured by Kendall tau. The results were considered significant when $p$ was $<0.05$. All analyses were conducted using the SPSS, version 20.0 (SPSS, Inc., Chicago, Illinois, USA).

\section{RESULTS}

In this study, a total of 3,456 patients with IBD [1985 (57.4\%) males and 1,471 (42.6\%) females] with an average age of $41.6 \pm 4.24$ years were studied, including $80(2.3 \%)$ infected elderly patients, 227 (6.6\%) non-infected elderly patients, and 405 (11.7\%) infected adult patients. Additionally, 307 (8.9\%) of 3,456 IBD patients had opportunistic infections. The infection rate of elderly patients was $16.5 \%$ (80/485), which was significantly higher than $7.6 \%$ $(227 / 2971)$ of adult patients ( $p<0.001)$. As shown in Table I, infected elderly group had longer hospital stay and more treatment costs compared with infected adult group and non-infected elderly group $(p<0.05)$. Compared with infected adult group, fever and abdominal pain were less common in the infected elderly group ( $p<0.05)$. Compared with the non-infected elderly group, fever, diarrhea, and abdominal pain were more common in the infected elderly group ( $p<0.05)$.

Fifty-three patients in the infected elderly group had hypoproteinemia (66.3\%). This incidence of hypoproteinemia was higher than that in the infected adult group (52.4\%) and non-infected elderly group $(46.9 \%, p<0.05)$. Compared with the infected adult group, the infected elderly group was less likely to have anemia, increased leukocyte count and platelet count $(p<0.05$ ). Several activity of IBD were more frequent in infected elderly group than in infected adult group and in non-infected elderly group ( $p<0.05$ ).

As shown in Table II, viral infections were the most frequently occurring infectious agents in elderly (66.3\%) and young $(70.5 \%)$ patients with IBD. CMV infection was the most common in the infected elderly group (37.5\%), while 
EBV infection was the most common in the infected adult group $(36.1 \%)$. The bacterial infection rate in the infected elderly group $(45.0 \%)$ was higher than that in the infected adult group $(32.6 \%, p<0.05)$. Elderly IBD patients were more likely to have multiple pathogen (two pathogens or more) infections compared with young IBD patients ( $p$ $<0.05$ ). For infected elderly patients, there were 24 patients in intestinal infection group and 56 patients in parenteral infection group. The infection rate was $11.5 \%(56 / 485)$ in the parenteral infection group, as compared to $4.9 \%(24 / 485)$ in the intestinal infection group ( $p<0.001)$. In addition, we found a significant association between parenteral infection group and several activity of IBD in elderly infected group (Kendall's tau-a $=0.265, p=0.017$ ), but no significant association was found in adult infected group (Kendall's tau- $a=$ $0.106, p=0.110)$.

Seventy-five percent $(60 / 80)$ of elderly infected patients and $82.4 \%(187 / 227)$ of young infected patients had a stable response, but $23.8 \%(19 / 80)$ of elderly infected patients and $17.6 \%(40 / 227)$ of young infected patients had SIRS. One elderly infected patient did not achieve remission, progressively deteriorated, and died during the course of therapy. There was no significant difference in the clinical remission rates (infected elderly group versus infected adult group, $75.0 \%$ vs. $82.4 \%, p=0.152$ ), SIRS rates (infected elderly group versus infected adult group, $23.8 \%$ vs. $17.6 \%, p=$ 0.232 ), death rates (infected elderly group versus infected adult group, $1.3 \%$ vs. $0.0 \%, p=0.261$ ) with two groups. Figures 1 and 2 show opportunistic infections ( $\geq 3$ times) was much more common in infected elderly group than in infected adult group $(8.8 \%$ vs. $2.2 \%, p=0.016)$. The times of opportunistic infections may be associated with the incidence of SIRI in elderly infected group (Kendall's tau$a=0.291, p=0.008)$. In regression analysis, elderly patients, who suffered two times of opportunistic infections, have 3.556 times the SIRS risk of those who suffered one times of opportunistic infections (OR 3.556; $95 \% \mathrm{Cl}$ : 1.014-12.467, $p=0.048$ ); elderly patients who suffered their times of opportunistic infections have 5.333 times the SIRI risk of those who suffered one times of opportunistic infections (OR 5.333; 95\% Cl: 1.123-25.331, $p=0.035$ ). However, no correlation was found between the times of opportunistic infections and SIRI in young elderly group (Kendall's tau$a=0.111, p=0.091$ ).

As Table III indicates, multivariate regression showed that age $\geq 60$ years $(p=0.029$, or $p=2.542)$, corticosteroids ( $p$ $=0.028, O R=2.133)$, immunosuppressants $(p<0.001, O R=$ 3.612) and biological agents ( $p=0.003$, or $p=3.772$ ) were independent risk factors for IBD patients. Patient's gender, smoking habit, use of aminosalicylic acid, and presence of hypertension and diabetes were not associated with an increased risk of opportunistic infection in multivariate regression.

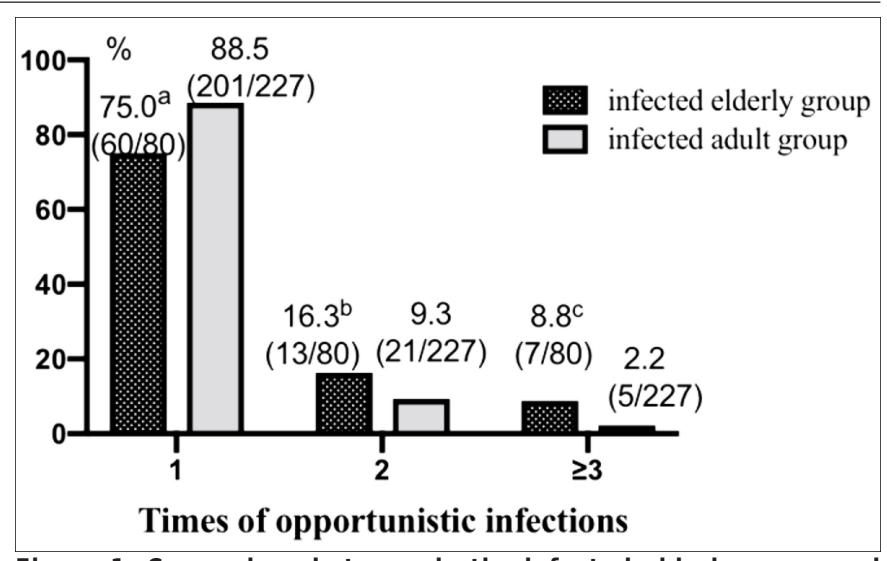

Figure 1: Comparison between in the infected elderly group and infected adult group in the times of opportunistic infection. ${ }^{\text {a }} p=0.004$ versus infected adult group (1 time of opportunistic infection); ${ }^{b} p=0.086$ versus infected adult group (2 times of opportunistic infection ); ${ }^{c} p=0.016$ versus infected adult group ( $\geq 3$ times of opportunistic infection).

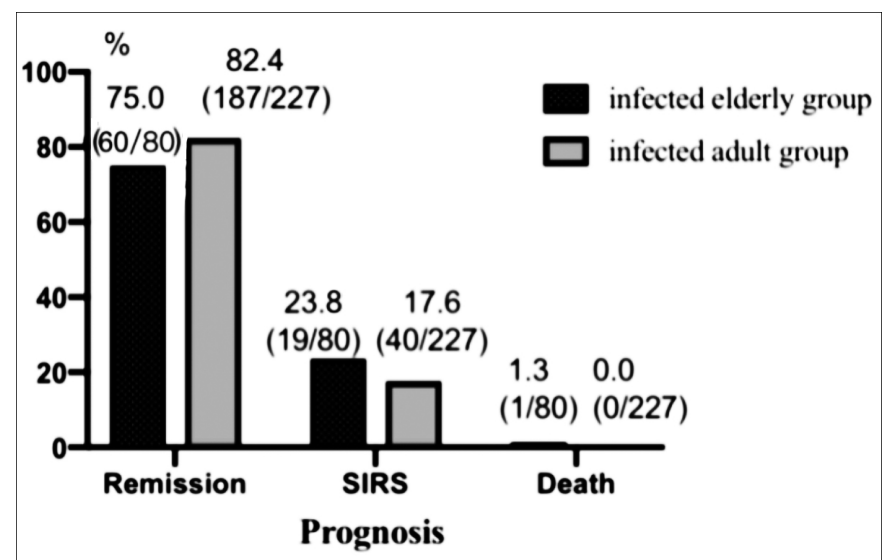

Figure 2: Comparison of prognosis between in the infected elderly group and infected adut group.

${ }^{a} p=0.152$, versus infected adult group in Remission rates; ${ }^{b} p=0.232$, versus infected adult group in SIRI rates; ${ }^{c} p=0.261$ versus infected adult group in death rates.

\section{DISCUSSION}

Patients with IBD have a high risk of opportunistic infections, and the prevalence of opportunistic infections has been reported to be much higher in elderly IBD patients than young IBD patients. ${ }^{9,13,14}$ Previous domestic reports have indicated that the opportunistic infection rate is about $15.0 \%$ in hospitalised IBD patients (age $>50$ years). ${ }^{9}$ This study found that the opportunistic infection rate of elderly hospitalised patients $(16.5 \%)$, which is significantly higher than that of young hospitalised patients ( $7.6 \%$ ), and that age $\geq 60$ years is an independent risk factor of opportunistic infection. The reasons for the increased risk of opportunistic infection in elderly IBD patients are varied, but the main reason is that elderly patients have a decreased immune function because of aging. It leads to a decrease in the number of haematopoietic stem cells results in downstream thymic atrophy and decrease number and functional status of B-lymphocyte and T-lymphocyte. ${ }^{7,15,16}$ Furthermore, treatment with corticosteroids, immunosuppressants, biological agents and malnutri- 
tion were also important drivers of opportunistic infection caused by decreased immune function. ${ }^{5}$

In this study, most of elderly infected patients had atypical clinical presentation. Elderly IBD patients often developed opportunistic infection without fever and leukocytosis, but they are prone to diarrhea, hypoproteinemia and several activity of IBD. There was a positive relationship between parenteral infection and several IBD in elderly patients. The IBD patients, who were accompanied by concomitant bloodstream and pulmonary infection, may have weakened immunity, aggravating the IBD. ${ }^{9,13}$ This finding indicates that for elderly IBD patients, one should have high suspicion for opportunistic infection when IBD disease has several activities even in the absence of fever and leukocytosis. Hypoproteinemia, which might be caused by worsening diarrhea and hematochezia with opportunistic infection, was more prevalent in infected elderly group in this study. However, hypoproteinemia and malnutrition may bring damage to complement system, lower the level of protein, and weaken the immunity. ${ }^{17}$ This makes them more vulnerable to opportunistic infections. So, between malnutrition and opportunistic infection, this may be a vicious cycle. Appropriate nutritional support, together with the conventional treatment, is particularly important for elderly IBD patients with opportunistic infection.

Viral infections were frequently observed in IBD patients (more than $60 \%$ ) and elderly IBD patients were at a higher risk of CMV infection, which was consistent with previous studies. ${ }^{18}$ This may be because TNF- $\alpha$ expressed in UC activates CMV, while IFN-y expressed in CD inhibits CMV. ${ }^{18,19}$ In previous study, UC was observed more frequently than CD in elderly patients. So elderly patients are more susceptible to CMV infection.19 Concurrent corticosteroid use and hospitalisation within one month were associated with CDI.20 In this study, CDI mainly infects the intestines and occurred in $37.5 \%$ elderly IBD patients, who had a longer hospital stay (about 21 days on average) and higher risk of opportunistic infection when treated with corticosteroid. It is, therefore, suggested that those elderly patients have long hospital stay with corticosteroid therapy, under the monitor of the CDI infection.

Although no statistical difference was found in remission and SIRI rates between elderly and young infected patients, elderly patients were more likely to have multiple infections, and the times of opportunistic infections was associated with SIRI. This means that for elderly IBD patients, the higher the number of infections, the worse the prognosis. In addition, the use of corticosteroids, immunosuppressants, and biological agents was also the risk factors of opportunistic infection in patients with IBD, which was consistent with previous studies. ${ }^{13,21}$ These treatments work in different ways and mechanisms, but all may alter immune responsiveness to varying degree. 5 Immunosuppressants can selectively inhibit the activation and proliferation of Iymphocytes, decrease the expression of proinflammatory cytokines, and azathioprine or 6-Mercaptopurine can inhibit de novo synthesis of RNA and DNA. ${ }^{22,23}$ When corticosteroids are used in large amounts or for longer period of time, the number of B-lymphocytes in the spleen and lymph nodes decrease remarkably, immunoglobulin degradation is increased, and synthesis is inhibited.24 Additionally, TNF-inhibitors play an anti-inflammatory role by blocking TNF-a from binding to its cell surface receptors and promoting the apoptosis of inflammatory cells, though they might increase the risk of opportunistic infections. ${ }^{25}$

However, there were some limitations in this study. Firstly, the population were all inpatients and the three institutions were all tertiary referral hospitals, which tend to see sicker patients with IBD, and there may be selective bias. Secondly, IBD patients younger than 18 years were not included, so the difference between elderly IBD patients and younger IBD patients ( $<18$ years) with opportunistic infection was not clear.

\section{CONCLUSION}

Elderly IBD patients are at higher risk of opportunistic infection due to decreased immunity, malnutrition and the use of corticosteroids or immunosuppressants. The atypical clinical manifestations of infection and poor prognosis not only increase the difficulty of diagnosis and treatment, but also increase healthcare burden. Thus, clinician should pay attention to this activity. Therefore, it is important to closely monitor elderly patients to enable early detection and management of opportunistic infection, and to provide appropriate nutritional support.

\section{DISCLOSURE:}

The present work was supported by the National Natural Science Foundation of China (No 81470826), the Science Foundation from Science \& Technology Department of Sichuan Province (No. 2019YFS0262); and 1.3.5 Project For Disiplines Of Excellence, West China Hospital, Sichuan University (No.ZYGD18023).

\section{ETHICAL APPROVAL:}

Ethics Committee approval was received from the Ethics Committee of West China Hospital of Sichuan University (Number: 2018242).

\section{PATIENTS' CONSENT:}

Informed consents were obtained from all participants or their family.

\section{CONFLICT OF INTEREST:}

The authors declared no conflict of interest.

\section{AUTHORS' CONTRIBUTION:}

JQZ: Conception and design, data acquisition and analysis, interpretation, drafting, final approval.

ZMM: Design, critical revision, final approval.

TZ: Interpretation, critical revision, final approval.

XTJ: Analysis and interpretation, drafting, final approval.

HTG: Conception and design, interpretation, critical revision, final approval.

\section{REFERENCES}

1. Taleban S, Colombel JF, Mohler MJ, Fain MJ. Inflammatory 
bowel disease and the elderly: a review. J Crohns Colitis 2015; 9(6):507-15. doi: 10.1093/ecco-jcc/jjv059.

2. Matsumoto S, Miyatani H, Yoshida Y. Ulcerative colitis: Comparison between elderly and young adult patients and between elderly patients with late-onset and long-standing disease. Dig Dis Sci 2013; 58(5):1306-12. doi: 10.1007/s10620-012-2517-5.

3. Lakatos PL, David G, Pandur T, Erdelyi Z, Mester G, Balogh M, et al. IBD in the elderly population: results from a population-based study in Western Hungary, 1977-2008. J Crohns Colitis 2011; 5(1):5-13. doi: 10.1016/j.crohns.2010.08.004.

4. Wheat CL, Ko CW, Clark-Snustad K, Grembowski D, Thornton TA, Devine B. Inflammatory Bowel Disease (IBD) pharmacotherapy and the risk of serious infection: a systematic review and network meta-analysis. BMC Gastroenterol 2017; 17(1):52. doi: 10.1186/s12876-017-0602-0.

5. Rahier JF, Magro F, Abreu C, Armuzzi A, Ben-Horin S, Chowers $Y$, et al. European Crohn's and Colitis Organisation (ECCO). Second European evidence-based consensus on the prevention, diagnosis and management of opportunistic infections in inflammatory bowel disease. J Crohns Colitis 2014; 8(6): 443-68. doi: 10.1016/j.crohns.2013.12.013.

6. Gauss A, Rosenstiel S, Schnitzler P, Hinz U, Rehlen T, Kadmon $M$, et al. Intestinal cytomegalovirus infection in patients hospitalized for exacerbation of inflammatory bowel disease: A 10year tertiary referral center experience. Eur J Gastroenterol Hepatol 2015; 27(6):712-20. doi: 10.1097/MEG. 0000000 000000361.

7. Weng NP. Aging of the immune system: how much can the adaptive immune system adapt? Immunity 2006; 24(5):495-9. doi: 10.1016/j.immuni.2006.05.001.

8. Frolova L, Drastich P, Rossmann P, Klimesova K, Tlaskalova-Hogenova $\mathrm{H}$. Expression of Toll-like receptor 2 (TLR2), TLR4, and CD14 in biopsy samples of patients with inflammatory bowel diseases: upregulated expression of TLR2 in terminal ileum of patients with ulcerative colitis. J Histochem Cytochem 2008; 56(3):267-74. doi: 10.1369/jhc.7A7303. 2007.

9. Kirchgesner J, Lemaitre M, Carrat F, Zureik M, Carbonnel F, Dray-Spira R. Risk of serious and opportunistic infections associated with treatment of inflammatory bowel diseases. Gastroenterology 2018; 155(2):337-346.e10. doi: 10.1053/j.gastro.2018.04.012.

10. D'Haens G, Sandborn WJ, Feagan BG, Geboes K, Hanauer SB, Irvine EJ, et al. A review of activity indices and efficacy end points for clinical trials of medical therapy in adults with ulcerative colitis. Gastroenterology 2007; 132(2):763-86. doi: 10.1053/j.gastro.2006.12.038.

11. Best WR, Becktel JM, Singleton JW, Kern F Jr. Development of a Crohn's disease activity index. National Cooperative Crohn's Disease Study. Gastroenterology 1976; 70(3):439-44. PMID: 1248701.

12. Kaukonen KM, Bailey M, Pilcher D, Cooper DJ, Bellomo R. Systemic inflammatory response syndrome criteria in defining severe sepsis. N Engl J Med 2015; 372(17): 1629-38. doi: 10.1056/NEJMoa1415236.

13. Naganuma M, Kunisaki R, Yoshimura N, Takeuchi $Y$,
Watanabe M. A prospective analysis of the incidence of and risk factors for opportunistic infections in patients with inflammatory bowel disease. J Gastroenterol 2013; 48(5): 595-600. doi: 10.1007/s00535-012-0686-9.

14. Toruner M, Loftus EV Jr, Harmsen WS, Zinsmeister AR, Orenstein R, Sandborn WJ, et al. Risk factors for opportunistic infections in patients with inflammatory bowel disease. Gastroenterology 2008; 134(4):929-36. doi: 10.1053/j.gastro. 2008.01.012.

15. Nguyen QP, Deng TZ, Witherden DA, Goldrath AW. Origins of CD4+ circulating and tissue-resident memory T-cells. Immunology 2019; 157(1):3-12. doi: 10.1111/imm.13059.

16. Crooke SN, Ovsyannikova IG, Poland GA, Kennedy RB. Immunosenescence: A systems-level overview of immune cell biology and strategies for improving vaccine responses. Exp Gerontol 2019; 124:110632. doi: 10.1016/j. exger.2019. 110632.

17. Alwarawrah Y, Kiernan K, Maclver NJ. Changes in Nutritional Status Impact Immune Cell Metabolism and Function. Front Immunol 2018; 9:1055. doi: 10.3389/fimmu.2018.01055.

18. Shi HY, Chan FK, Leung WK, Li MK, Leung CM, Sze SF, et al. Natural History of Elderly-onset Ulcerative Colitis: Results from a Territory-wide Inflammatory Bowel Disease Registry. J Crohns Colitis 2016; 10(2):176-85. doi: 10.1093/ecco-jcc/jjv194.

19. Nakase H, Yoshino T, Honzawa $Y$, Chiba T. Low prevalence of CMV infection in patients with Crohn's disease in comparison with ulcerative colitis: effect of different immune response on prevalence of CMV infection. Dig Dis Sci 2010; 55(5):1498-9. doi: 10.1007/s10620-010-1162-0.

20. Li Y, Xu H, Xu T, Xiao M, Tang H, Wu D, et al. Case-Control Study of Inflammatory Bowel Disease Patients with and without Clostridium difficile Infection and Poor Outcomes in Patients Coinfected with C. difficile and Cytomegalovirus. Dig Dis Sci 2018; 63(11):3074-3083. doi: 10.1007/s10620018-5230-1.

21. Ford AC, Peyrin-Biroulet L. Opportunistic infections with anti-tumor necrosis factor-therapy in inflammatory bowel disease: meta-analysis of randomized controlled trials. Am J Gastroenterol 2013; 108(8):1268-76. doi: 10.1038/ajg. 2013.138.

22. Lee RA, Gabardi S. Current trends in immunosuppressive therapies for renal transplant recipients. Am J Health Syst Pharm 2012; 69(22):1961-75. doi: 10.2146/ajhp110624.

23. Clinical and Research Information on Drug-Induced Liver Injury [Internet]. Bethesda (MD): National Institute of Diabetes and Digestive and Kidney Diseases; 2012. Purine Analogues 2014 Jul 14. PMID: 31643909.

24. Osterman MT, Haynes K, Delzell E, Zhang J, Bewtra M, Brensinger $\mathrm{CM}$, et al. Effectiveness and safety of immunomodulators with anti-tumor necrosis factor therapy in Crohn's disease. Clin Gastroenterol Hepatol 2015; 13(7):12931301.e5; quiz e70, e72. doi: 10.1016/j.cgh.2015.02.017.

25. Nakase $H$, Chiba T. TNF-alpha is an important pathogenic factor contributing to reactivation of cytomegalovirus in inflamed mucosa of colon in patients with ulcerative colitis: lesson from clinical experience. Inflamm Bowel Dis 2010; 16(4):550-1. doi: 10.1002/ibd.21047. 